\title{
Modeling dynamic phenomena in 3-way catalytic converters
}

\author{
Grigorios C. Koltsakis, Anastasios M. Stamatelos* \\ Laboratory of Applied Thermodynamics, Aristotle University Thessaloniki, 54006 Thessaloniki, Greece
}

\begin{abstract}
Mathematical modeling of 3-way catalytic converter (3WCC) operation is increasingly employed in automotive catalyst and converter systems optimization. The majority of the models employed in this direction employ a 'quasi-steady' approach in the reaction kinetics computations. This approach is useful in predicting real-world performance of the catalyst. However, certain improvements, that are produced by the application of specially tuned redox oscillations, can not be predicted. This paper presents an approach embodying certain types of dynamic phenomena into an existing 3-WCC quasi-steady model. The dynamic model developed according to this approach is validated against literature data and results from experimental investigations. It is confirmed, that the catalyst behavior under dynamic exhaust composition conditions significantly differs from what is predicted under the quasi-steady-state assumption. More specifically, oxygen storage and the transient character of water gas shift reaction are shown to affect dynamic behavior. The results of this investigation encourage further application of mathematical modeling in areas like lambda control strategy optimization, which lied beyond the scope of traditional 3WCC models. (C) 1999 Elsevier Science Ltd. All rights reserved.
\end{abstract}

Keywords: Automotive emissions; Catalytic converters; Mathematical modeling; Dynamic behavior; Reaction kinetics

\section{Introduction}

The 3-way catalytic converter, an indispensable device for the control of $\mathrm{CO}, \mathrm{HC}$ and $\mathrm{NO}_{x}$ emissions of gasoline engines, is a chemical reactor operating at highly transient conditions. The temperature, flow rate and composition of the exhaust gas flowing through the converter honeycomb monolith change significantly according to the driving mode, with a typical time scale of several seconds. At the same time, the closed-loop control of the fuel management system induces further, more severe, transients of the feed gas composition with a typical time scale of less than a second.

The latter effect is attributed to the interaction between the engine and the lambda sensor (Bozek et al., 1992), which is used as a feedback control signal for the fuel injection system in order to ensure that a stoichiometric fuel-air mixture is supplied in the engine cylinders. However, the systems response lag (mainly attributed to the exhaust gas travel time and the sensor's response delay)

\footnotetext{
* Corresponding author. Tel.: + 30-31-996066; fax: + 30-31-996019.
}

E-mail address: tassos@antiopi.meng.auth.gr (A. M. Stamatelos) causes the air-to-fuel ratio to oscillate around the stoichiometric value with the limit cycle frequency of the control system.

The behavior of the three-way catalytic converter under such dynamic conditions presents therefore high practical interest. Since the beginning of the previous decade, it has been recognized that the three-way catalyst efficiency is significantly affected when the composition of the feed gas is oscillating with different amplitudes and frequencies (Shulman et al., 1982; Herz et al., 1983; Taylor and Sinkevitch, 1983; Schlatter et al., 1983; Matsunaga et al., 1987). This behavior is mainly attributed to the ability of some washcoat components to be periodically oxidized and reduced depending on the exhaust gas redox environment. For example, the activity of the noble metals $\mathrm{Pt}, \mathrm{Pd}$ and $\mathrm{Rh}$ depends on their oxidation state and is lowered for higher oxidation levels (Diwell et al., 1991; Nunan et al., 1991).

The advent of stricter US and European emission standards has increased the need for reliable 3-way catalytic converter models supporting the design of demanding exhaust systems. A number of mathematical models working in this direction are already presented in the literature and employed in optimization procedures $(\mathrm{Oh}$ and Cavendish, 1985; Pattas et al., 1994; Siemund et al., 
1996). On the other hand, the research on the effect of oscillating $\mathrm{A} / \mathrm{F}$ has been restricted mainly to experimental testing and empirical explanations of results. In a number of previous papers, a mathematical modeling approach has been presented, aiming at the simulation of the transient adsorption, desorption and surface reactions occurring in a 3-way catalyst under oscillating A/F conditions with simple gas mixtures. Such models are considered difficult to apply in realistic automotive conditions, where many interacting exhaust species are present and participating in many heterogeneous reactions.

In this work, an alternative approach to model highly transient phenomena in catalytic converters is presented. First, the most important dynamic phenomena are recognized based on literature research. Simple, tunable models are developed to describe these phenomena, which are then embodied in a 'quasi-steady' model. A series of simple published experimental tests are employed to support the validity of the approach and tune the basic kinetic parameters involved.

Having established the mathematical model, the transient behavior of the 3-WCC is studied during A/F scanning from lean-to-rich exhaust environment and vice versa. The effect of $\mathrm{A} / \mathrm{F}$ oscillations superimposed on the $\mathrm{A} / \mathrm{F}$ scan is also studied using experimental measurements and model computations. The model predictions are also compared to those computed with the 'quasi-steady' assumption. The ability of the model to predict catalyst behavior under oscillating $\mathrm{A} / \mathrm{F}$ conditions is discussed.

\section{Transient 3-WCC model}

As mentioned in the introduction section, a previously developed 3-WCC mathematical model will be extended and equipped with submodels of the main dynamic phenomena. A detailed description of the basic model can be found in a previous authors' work (Koltsakis et al., 1997). The basic features of the 'quasi-steady' mathematical model can be summarized as follows:

- Computation of the convective heat and mass transfer from the exhaust gas to the catalytic surface. A 'film approach' is adopted employing mean bulk values for the gas-phase and solid-gas interface values for the solid-phase species concentrations.

- Computation of the heterogeneous chemical reactions taking place on the catalytic surface based on Langmuir-Hinshelwood-based rate expressions. 'Lumping' of surface adsorption/desorption and pore diffusion phenomena in the kinetic rate expressions.

- The 2-D transient temperature field in the cylindrical converter is computed taking into account the heat conduction in the substrate and the surrounding insulation and the heat losses to the surroundings via convection and radiation.
Detailed formulation of the energy and mass balance equations as well as the solution procedure followed are described in detail by Koltsakis et al. (1997). As with all 'quasi-steady' models the computation of the species concentrations and the reaction rates is based on the equation of the diffusion and the reaction rates for each species $j$ :

$\dot{n}_{i, j}\left(c_{g, i, j}, c_{s, i, j}\right)=R_{i, j}\left(\mathbf{c}_{s, i}, T_{s, i}\right)$

The left-hand side part of the equation concerns the mass diffusion rate resulting from the concentration gradient between gas bulk phase and wall. The reaction rates $R_{j}$ (right-hand side) are non-linear functions of the local temperature and composition at the gas-solid interface. The reactions, kinetic expressions and kinetic constants used in the present model are listed in Appendix A.

According to Eq. (1), the rates of reaction and mass transfer to the catalytic surface are always in equilibrium, implying that there is no species accumulation phenomena on the solid catalytic surface. This assumption is realistic for steady-state operation, but not necessarily for operation under highly transient temperature and composition conditions. In the latter case, the employment of Eq. (1) with Langmuir-Hinshelwood-type expressions for the reaction rates, would probably not be sufficient. In order to account for the effects of transient adsorption-desorption and heterogeneous reaction phenomena, the kinetic model should include the detailed computation of the time-dependent surface coverage of each species on the active sites. Such models have been presented by a number of researchers (Oh et al., 1986; Nievergeld et al., 1994) for the case of a 1-D isothermal reactor with simple gas mixtures (up to three reacting species). These models aimed at studying the effects of oscillatory equivalence ratio on catalyst performance. However, the number of kinetic parameters needed for such a task are numerous and very difficult to estimate.

In our model, the quasi-steady approach expressed by Eq. (1) is retained, while highly transient effects, which are probably the most dominant for practical application cases are taken into account. Specifically, the phenomena considered to be of major importance are (Herz and Sell, 1985; Barshad and Gulari, 1985; Su and Rothchild, 1986):

- The oxygen storage and release phenomena in the washcoat are described by the dynamic redox activity of the Cerium oxides present in the catalytic layer. Tunable kinetic rate expressions are employed to represent catalyst performance in a wide range of temperature and redox environments

- Rh activity dependence on $\mathrm{Rh}$ oxidation state, as regards water-gas reaction is taken into account with a dynamic oxidation-reduction model.

This aims at keeping model complexity, and thus flexibility, to acceptable levels, at the same time profiting from 
the available experience regarding L-H kinetic rate expressions for 3-way catalysts.

\section{Oxygen storage submodel}

The washcoat component, that seems to play the most important role in such dynamic oxidation-reduction phenomena is Cerium. Cerium is normally present in high quantities in the washcoat (order of $30 \mathrm{wt} \%$ or 1000 $\mathrm{g} / \mathrm{ft}^{3}$ ) and has multiple functions: stabilization of the washcoat layer and improvement of thermal resistance), enhancement of precious metal catalytic activity and function as an oxygen storage component.

The function of cerium as oxygen storage component is based on its ability to form both three and four valent oxides (Herz, 1981). Under net oxidizing conditions the following Ce oxide reaction is the most representative for the realization of oxygen storage:

$\mathrm{Ce}_{2} \mathrm{O}_{3}+\frac{1}{2} \mathrm{O}_{2} \rightarrow 2 \mathrm{CeO}_{2}$.

This reaction represents the storage of an oxygen atom by increasing the oxidation state of $\mathrm{Ce}_{2} \mathrm{O}_{3}$.

On the other hand, the $\mathrm{CeO}_{2}$ may function as an oxidizing agent of the exhaust gas species under net reducing conditions according to the following reactions:

$$
\begin{aligned}
& \mathrm{CO}+2 \mathrm{CeO}_{2} \rightarrow \mathrm{Ce}_{2} \mathrm{O}_{3}+\mathrm{CO}_{2}, \\
& \mathrm{C}_{x} \mathrm{H}_{y}+2\left(x+\frac{y}{2}\right) \mathrm{CeO}_{2} \rightarrow\left(x+\frac{y}{2}\right) \mathrm{Ce}_{2} \mathrm{O}_{3} \\
& \quad+x \mathrm{CO}+\frac{y}{2} \mathrm{H}_{2} \mathrm{O} .
\end{aligned}
$$

Each of the above reactions denotes the release of an oxygen atom, which is made available to react with a reducing species of the exhaust gas ( $\mathrm{CO}$ or $\mathrm{HC})$. We define the auxiliary number $\psi$ as

$\psi=\frac{2 x \mathrm{~mol} \mathrm{CeO}_{2}}{2 x \mathrm{~mol} \mathrm{CeO}_{2}+\mathrm{mol} \mathrm{Ce}_{2} \mathrm{O}_{3}}$

which can be considered as fractional extent of oxidation of the oxygen storage component. The extent of oxidation is changing continuously during transient converter operation and is affected by the relative reaction rates of reactions (2)-(4).

The rate of reaction (2) (oxidation rate) is expected to be proportional to the available active sites of 'reducedstate' Cerium oxides, which is expressed by the factor $\psi_{\text {cap }}(1-\psi)$. The rate should be also dependent on the prevailing oxygen concentration at the gas-solid interface. The linear dependence on $\mathrm{O}_{2}$ concentration is considered as a realistic assumption. The oxidation reaction rate is thus

$R_{\mathrm{ox}}=k_{\mathrm{ox}}(t) c_{s, \mathrm{O}_{2}} \psi_{\mathrm{cap}}(1-\psi)$, where $k_{\mathrm{ox}}$ is a characteristic rate constant, which exhibits an Arrhenius-type dependence on temperature:

$k_{\mathrm{ox}}=A_{\mathrm{ox}} \mathrm{e}^{-E_{\mathrm{ox}} / R T}$,

Analogous considerations are made for the reduction reactions rates. Here, the rates are expected to be directly proportional to $\psi_{\text {cap }} \psi$, and should exhibit a dependence on the local $\mathrm{CO}$ and $\mathrm{HC}$ concentration, respectively:

$R_{\text {red,CO }}=k_{\text {red,CO }}(T) c_{\mathrm{CO}} \psi_{\text {cap }} \psi$,
$R_{\text {red,HC }}=k_{\text {red,HC }}(T) c_{\text {HC }} \psi_{\text {cap }} \psi$
$R_{\text {red }}=R_{\text {red,CO }}+R_{\text {red,HC }}$

with

$k_{\text {red,CO }}=A_{\text {red,CO }} \mathrm{e}^{-E_{\text {red }} / R T}$,

$k_{\text {red,HC }}=A_{\text {red,HC }} \mathrm{e}^{-E_{\text {red }} / R T}$.

The variation of the oxidation extent $\psi$ should be computed at each location by the following differential equation:

$\frac{\mathrm{d} \psi}{\mathrm{d} t}=-\frac{1}{\Psi_{\text {cap }}}\left(R_{\mathrm{red}}+R_{\mathrm{ox}}\right)$

which is solved numerically by the implicit Euler method for each node, along the catalyst channels.

\section{4. $\mathrm{RH}$ redox submodel}

The water gas-shift reaction

$\mathrm{CO}+\mathrm{H}_{2} \mathrm{O} \rightarrow \mathrm{CO}_{2}+\mathrm{H}_{2}$

consumes further $\mathrm{CO}$ leaving more oxygen available for hydrocarbon oxidation. According to findings from other research works, this reaction can be catalyzed by $\mathrm{Rh}$ or $\mathrm{Pd}$, providing that the catalyst surface has undergone some extent of oxidation (Schlatter and Mitchell, 1980; Herz and Sell, 1985; Dictor, 1987; Barbier and Duprez, 1992).

The reversible oxidation-reduction process of the active catalyst is taken into account in the mathematical model by a submodel for the computation of active metal oxidation state. Assuming that the active metal for the water gas reaction is $\mathrm{Rh}$, we define $\theta_{\mathrm{Rh}}$ as the fraction of the Rh sites, that are oxidized (active). We consider, that the $\mathrm{Rh}$ oxidation and reduction rates can be expressed by the following general relations (Koltsakis, 1996):

$$
\begin{aligned}
& R_{\mathrm{ox}}=\left(1-\theta_{\mathrm{Rh}}\right) k_{\mathrm{Rh}, \mathrm{ox}} f_{\text {ox }}\left(\mathbf{c}_{j}\right) \\
& R_{\text {red }}=\theta_{\mathrm{Rh}} k_{\mathrm{Rh}, \text { red }} f_{\text {red }}\left(\mathbf{c}_{j}\right)
\end{aligned}
$$

The parameters $k_{\mathrm{Rh}, \mathrm{ox}} k_{\mathrm{Rh}, \text { red }}$ are exponential functions of temperature (an Arrhenius type dependence on temperature is assumed). The functions $f_{\text {ox }}\left(c_{j}\right), f_{\text {ox }}\left(c_{j}\right)$ denote the dependence of the reaction rates on the availability of 
oxidizing/reducing species. We can accept that the reaction rates are proportional to the oxygen atom equivalents of each species. Therefore,

$f_{\mathrm{ox}}\left(\mathbf{c}_{j}\right)=2 c_{\mathrm{O}_{2}}+c_{\mathrm{NO}}$,

$f_{\text {red }}\left(\mathbf{c}_{j}\right)=c_{\mathrm{CO}}+c_{\mathrm{H}_{2}}+\alpha_{f} c_{(\mathrm{HC})_{f}}+\alpha_{s} c_{(\mathrm{HC})_{s}}$

Having defined the oxidation and reaction rates, the temporal evolution of $\theta_{\mathrm{Rh}}$ is given by the following firstorder differential equation:

$\frac{\mathrm{d} \theta_{\mathrm{Rh}}}{\mathrm{d} t}=R_{\mathrm{ox}}-R_{\mathrm{red}}$

which is solved by the implicit Euler method.

\section{Step composition changes}

In this section, we will examine the ability of the dynamic model to simulate transient phenomena dealing with oxygen storage and water-gas reaction during step feed gas composition changes. For this purpose, the published experimental findings of Herz and Sell (1985) are exploited. The experiments were conducted with a $2620 \mathrm{~cm}^{3}$ catalyst installed in a $5.7 \mathrm{lt}$ engine. The GHSV was $50,000 \mathrm{~h}^{-1}$ and the exhaust gas temperature entering the converter between 740 and $750 \mathrm{~K}$. The exhaust gas composition as function of the $\mathrm{A} / \mathrm{F}$ ratio is given in Table 1. Stoichiometry corresponds to an $\mathrm{A} / \mathrm{F}$ value of 14.75 .

As will be described below, two different sets of experiments are conducted, each with three different catalysts. The first catalyst contains $\mathrm{Pt}, \mathrm{Rh}$ as the catalytically active noble metals and $\mathrm{Ce}$ as oxygen storage component. The second catalyst, which contains only $\mathrm{Pt} / \mathrm{Ce}$ is expected to show good oxygen storage properties and negligible potential for water gas reaction catalysis. On the contrary, the third catalyst, which contains only $\mathrm{Pt} / \mathrm{Rh}$ is expected to be active for water gas reaction but without oxygen storage abilities.

In the first experiment, a step $\mathrm{A} / \mathrm{F}$ change from 15.1 (lean) to 14.1 (rich) is imposed and the CO concentration at catalyst exit is recorded as function of time. The

Table 1

Exhaust gas composition employed in the experiments and simulations for the study of dynamic behavior under step composition changes (Herz and Sell, 1985)

\begin{tabular}{lll}
\hline & $\mathrm{A} / \mathrm{F}=14.1$ & $\mathrm{~A} / \mathrm{F}=15.1$ \\
\hline $\mathrm{CO}(\mathrm{vol} \%)$ & 1.3 & 0.28 \\
$\mathrm{HC}(\mathrm{vol} \%)$ & 0.062 & 0.04 \\
$\mathrm{NO}(\mathrm{vol} \%)$ & 0.099 & 0.1 \\
$\mathrm{O}_{2}(\mathrm{vol} \%)$ & 0.28 & 1.1 \\
$\mathrm{H}_{2}(\mathrm{vol} \%)$ & 0.43 & 0.093 \\
\hline
\end{tabular}

measured responses are presented in Fig. 1a. The expected CO response, assuming quasi-steady catalyst behavior is presented with dotted lines. During the first $20 \mathrm{~s}$ after the step composition change, an increased CO conversion compared with the steady-state case is observed for all three catalysts. Differences of the $\mathrm{CO}$ response between the three catalysts are clear.

According to the previous discussion, the $\mathrm{Pt} / \mathrm{Rh}$ catalyst is simulated with no oxygen storage capabilities. Based on the first catalyst results, the kinetics of the $\mathrm{Rh}$ redox reactions are tuned with trial and error in order to get an acceptable match, between experiment and simulation. Similarly, the measurement of the $\mathrm{Pt} / \mathrm{Ce}$ catalyst (no activity regarding the water-gas reaction) is employed to tune the oxygen storage submodel kinetics. Using the estimated kinetic constants for both phenomena, the $\mathrm{Pt} / \mathrm{Rh} / \mathrm{Ce}$ catalyst is modeled. The results of the computational simulation for all three catalysts are presented in Fig. 1b. The model ability to simulate the transient behavior of $\mathrm{CO}$ conversion in these cases is quite satisfactory.

In order to interpret the results, the stored oxygen and the Rh oxidation extent (averaged over the converter) are presented as functions of time for the three test cases in Fig. 1c. It can be initially observed that the time constants involved with these phenomena are of the same order of magnitude.

In the second experiment, the engine runs at a constant operation point with $\mathrm{A} / \mathrm{F}=14.1$. A lean excursion $(\mathrm{A} / \mathrm{F}=15.1)$ is imposed for $1 \mathrm{~s}$ and the engine returns to the previous rich operating point. The experimental results are presented in Fig. 2a. Based on the kinetics acquired with the previous experimental test case the catalyst response is simulated and the results are presented in Fig. 2b.

For the $\mathrm{Pt} / \mathrm{Ce}$ catalyst the $\mathrm{CO}$ response at catalyst exit, presents only minor differences compared to the expected quasi-steady behavior. This indicates, that the relatively small duration of the lean excursion was not enough for the catalyst to store sufficient oxygen, which would contribute after switching to the rich operating mode. The respective calculation shows that only $20 \%$ of the oxygen storage capacity is activated during the test (Fig. 2c).

On the other hand, the $\mathrm{Pt} / \mathrm{Rh}$ catalyst shows significant activity after the $\mathrm{A} / \mathrm{F}$ switch to its initial rich value. This implies that the $1 \mathrm{~s}$ duration of the lean excursion was enough to bring $\mathrm{Rh}$ to a substantial oxidation level. This is confirmed by the respective computation, which predicts a maximum value for the $\mathrm{Rh}$ oxidation fraction of $80 \%$.

If we examine the experimental results with the $\mathrm{Pt} / \mathrm{Rh} / \mathrm{Ce}$ catalyst, we can initially assess that the coexistence of $\mathrm{Rh}$ and $\mathrm{Ce}$ does not have a cumulative effect as regards $\mathrm{CO}$ conversion after step composition changes. It is interesting to note that this behavior is also predicted by the mathematical model. In fact, $\mathrm{Rh}$ 


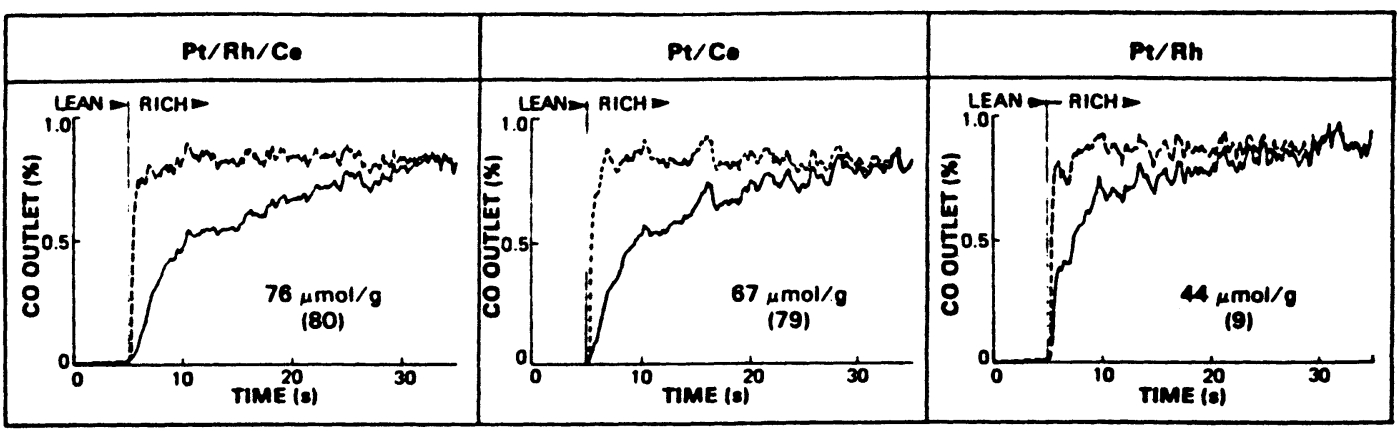

(a)
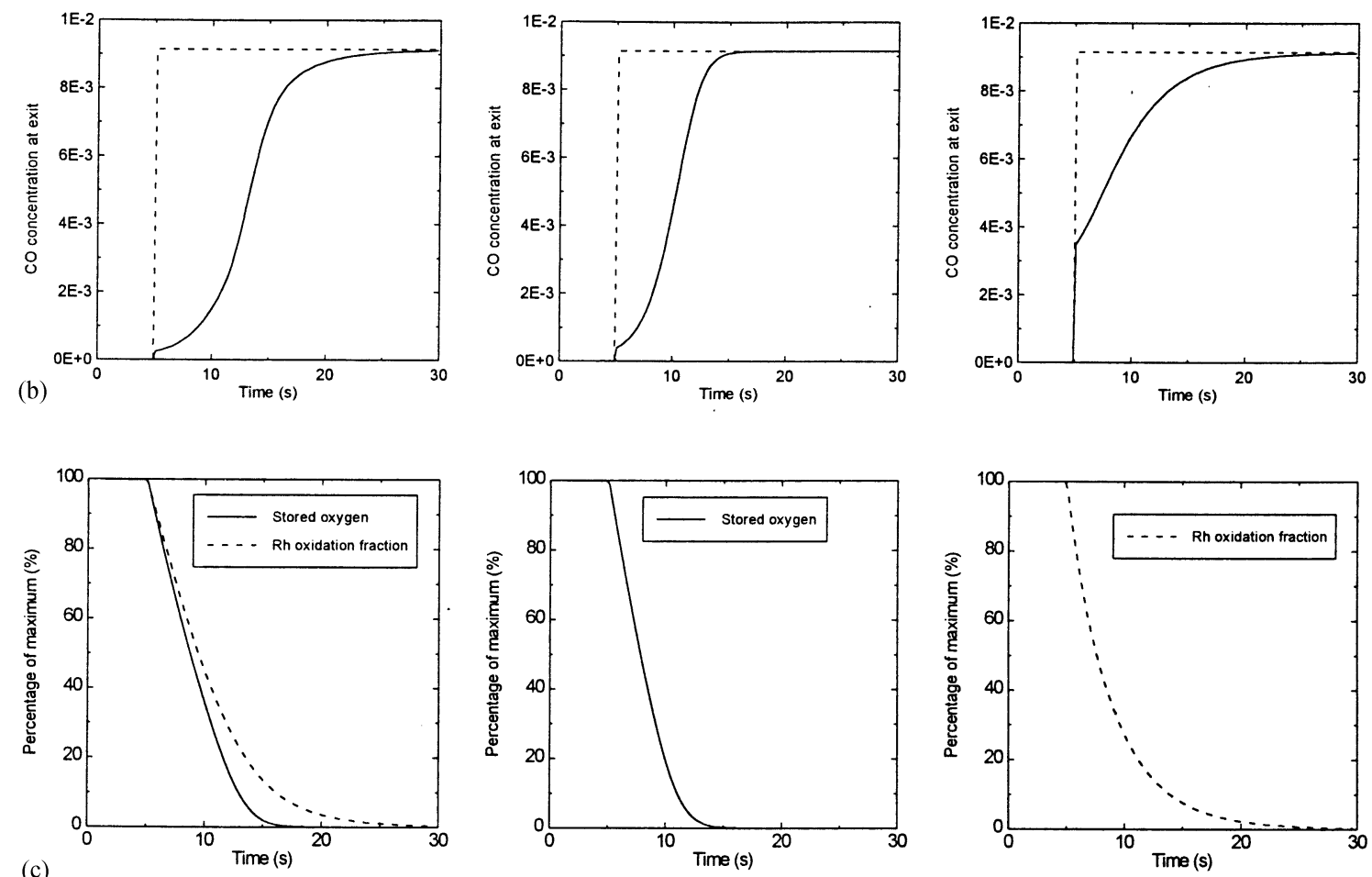

Fig. 1. Step composition change response. The A/F ratio is changed from 15.1 to 14.1 . The dotted lines correspond to the expected responses, if no dynamic effects were present (quasi steady state). (a) measurements of Herz and Sell (1985), (b) and (c) computed model results.

oxidation and oxygen storage reactions compete to consume the oxygen surplus during the short lean excursion. Due to the much higher quantity of Ce compared to Rh, $\mathrm{Rh}$ is more affected by this competence. This results in maximum $\mathrm{Rh}$ oxidation fraction of about $60 \%$ (compared to the $80 \%$ of the previous case).

\section{A/F scan}

In this section, results from selected laboratory tests are presented, together with respective mathematical model runs to illustrate some aspects of catalyst behavior during composition changes.

The $\mathrm{A} / \mathrm{F}$ scan test examines catalyst efficiency as function of $\mathrm{A} / \mathrm{F}$ ratio of the feed gas at a given temperature. In this test, variations of the $\mathrm{A} / \mathrm{F}$ ratio are produced by slowly changing the oxygen content of the simulated exhaust gas. In the specific test the $\mathrm{A} / \mathrm{F}$ is changed from 14.5 to 15.2 in a time period of $120 \mathrm{~s}$. The scan is realized in both directions, from rich to lean and vice versa. The feed gas inlet temperature is kept constant at $400^{\circ} \mathrm{C}$ and the space velocity is $75,000 \mathrm{~h}^{-1}$. The geometrical and thermophysical properties of the catalytic converter are given in Appendix B.

The measured catalyst efficiency as function of $\mathrm{A} / \mathrm{F}$ for the three species of interest is presented in Fig. 3. It is interesting to note that the efficiency curves are all dependent on the direction to which the $\mathrm{A} / \mathrm{F}$ scan is performed. Specifically, the A/F 'window' is wider for $\mathrm{CO}$ and $\mathrm{HC}$ when shifting from lean to rich environment, whereas the contrary is observed for NO. During transition from lean 


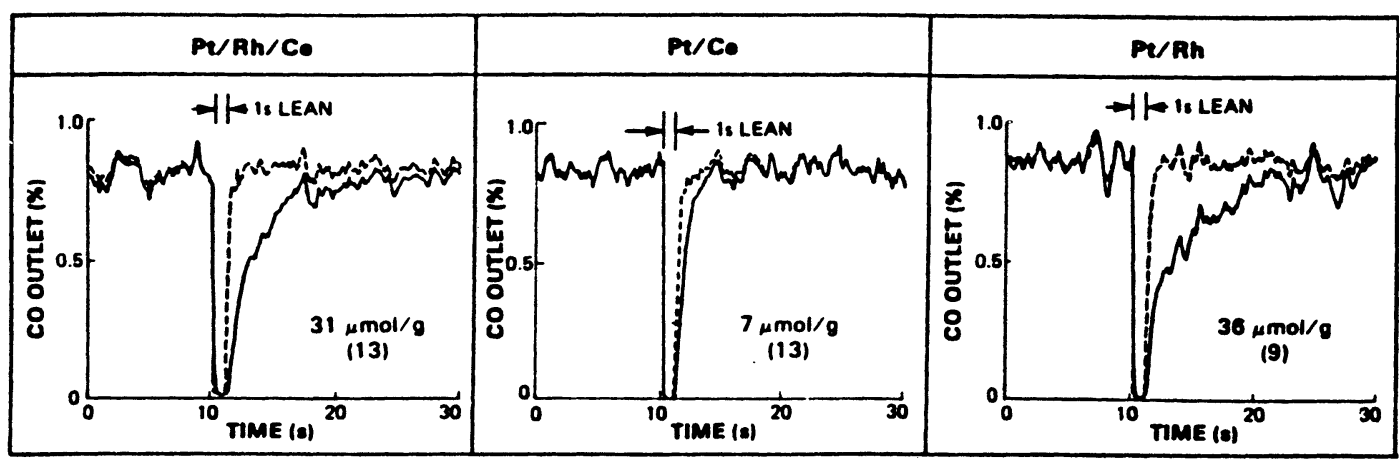

(a)
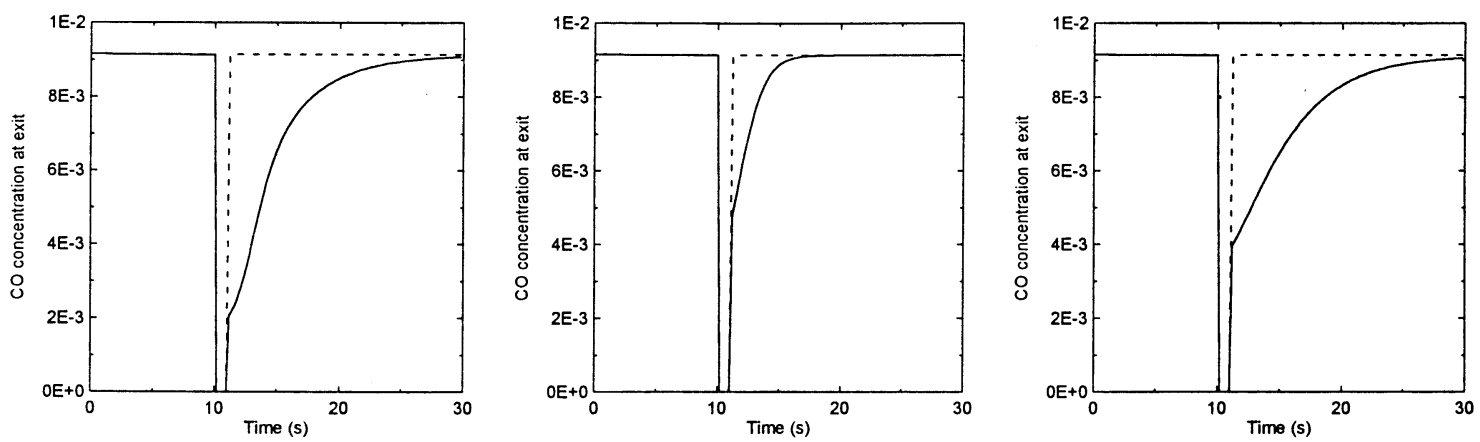

(b)
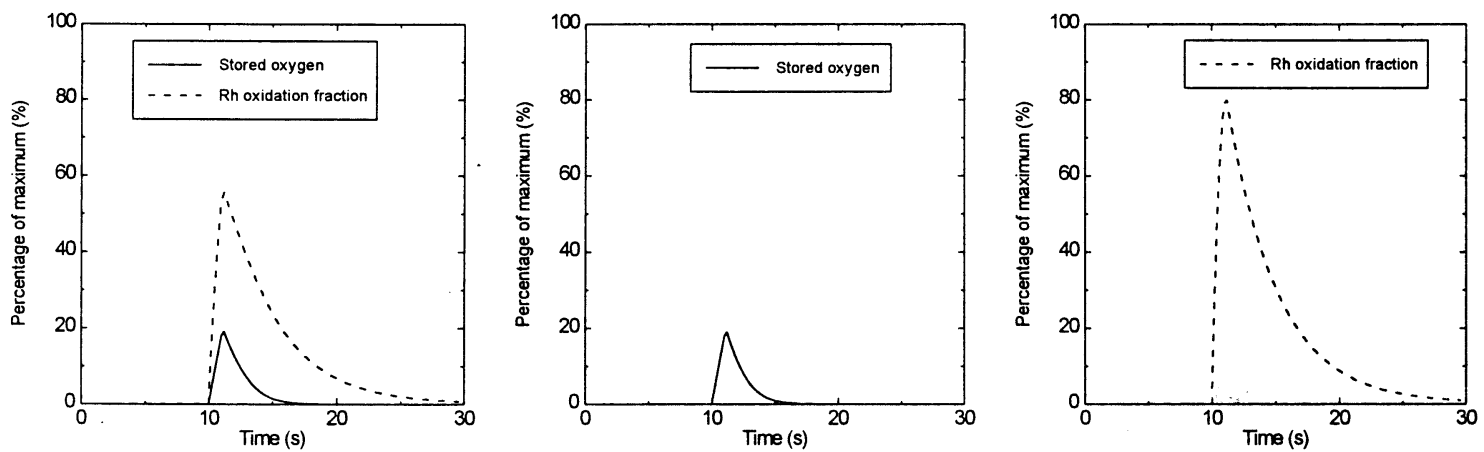

Fig. 2. Lean excursion experiment. The engine runs at a constant operation point with $\mathrm{A} / \mathrm{F}=14.1$. A lean excursion $(\mathrm{A} / \mathrm{F}=15.1)$ is imposed for $1 \mathrm{~s}$ and the engine returns to the previous rich operating point. The dotted lines correspond to the expected responses, if no dynamic effects were present (quasi-steady state). (a) measurements of Herz and Sell (1985), (b) and (c) computed model results.

to rich environment, the catalyst preserves a higher activity for $\mathrm{CO}$ and $\mathrm{HC}$, which can be attributed to the previously stored oxygen. At the same time, the lower availability of $\mathrm{CO}$ and $\mathrm{HC}$ limits the $\mathrm{NO}$ conversion capability.

The dynamic mathematical model was employed to simulate the above phenomena. Fig. 4 presents the computed results of the simulation of the previously described A/F scan test. It can be observed, that the model can successfully describe the catalyst efficiency as function of the A/F. Furthermore, the model predicts the dependence of catalyst efficiency on the direction of the $\mathrm{A} / \mathrm{F}$ scanning. This is apparently due to the successful simulation of the dynamic phenomena (oxygen storage and water gas reaction).

Fig. 5 presents the quantity of stored oxygen and the $\mathrm{Rh}$ oxidation fraction during the $\mathrm{A} / \mathrm{F}$ scan test, as computed by the mathematical model. After extensive lean operation the amount of stored oxygen is the maximum possible $\left(60 \mathrm{~mol} / \mathrm{m}^{3}\right.$ in our case). During transition from lean-to-rich region, the stored oxygen is gradually consumed, while the storage rate is decreased. After the stored oxygen reaches a minimum value, it then starts to increase, as we move towards the lean region. The storage rate is actually higher than the release rate, which is in accordance with previous relative findings (Herz, 1987). 


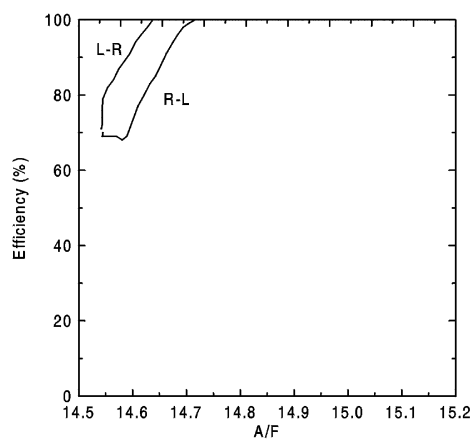

$\mathrm{CO}$

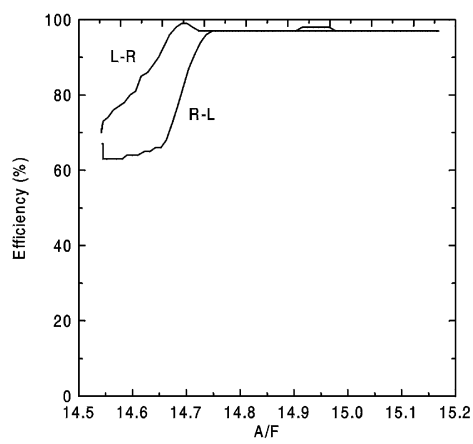

$\mathrm{HC}$

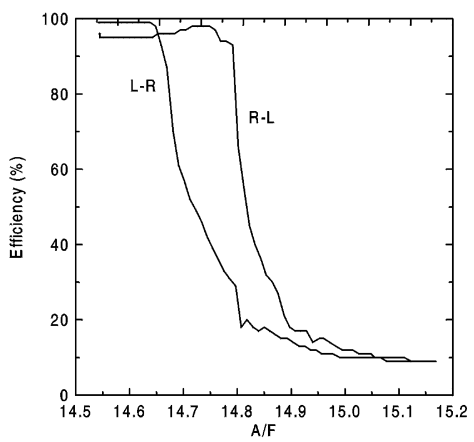

$\mathrm{NO}_{\mathrm{x}}$

Fig. 3. Measured catalyst conversion efficiency as function of $\mathrm{A} / \mathrm{F}$ during transition from lean to rich environment and vice versa.

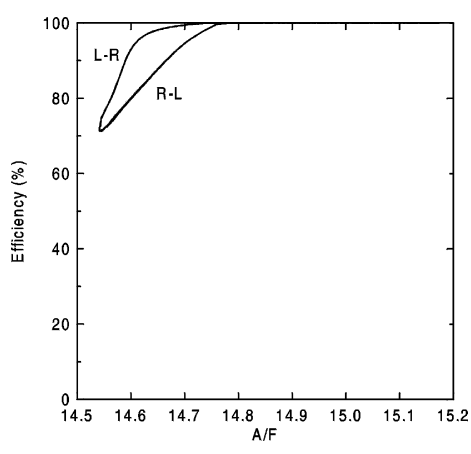

$\mathrm{CO}$

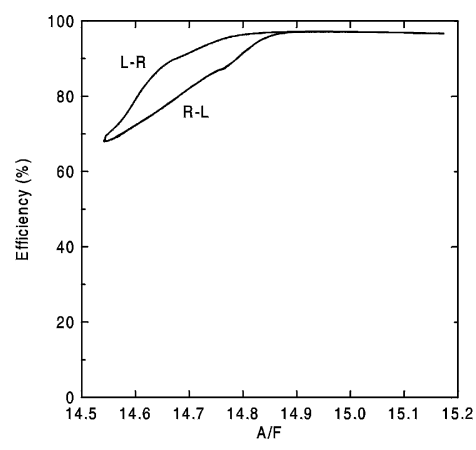

$\mathrm{HC}$

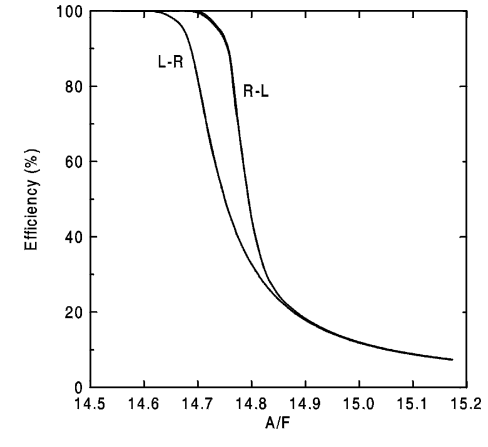

$\mathrm{NO}_{\mathrm{x}}$

Fig. 4. Computed catalyst conversion efficiency as function of $\mathrm{A} / \mathrm{F}$ during transition from lean to rich environment and vice versa.
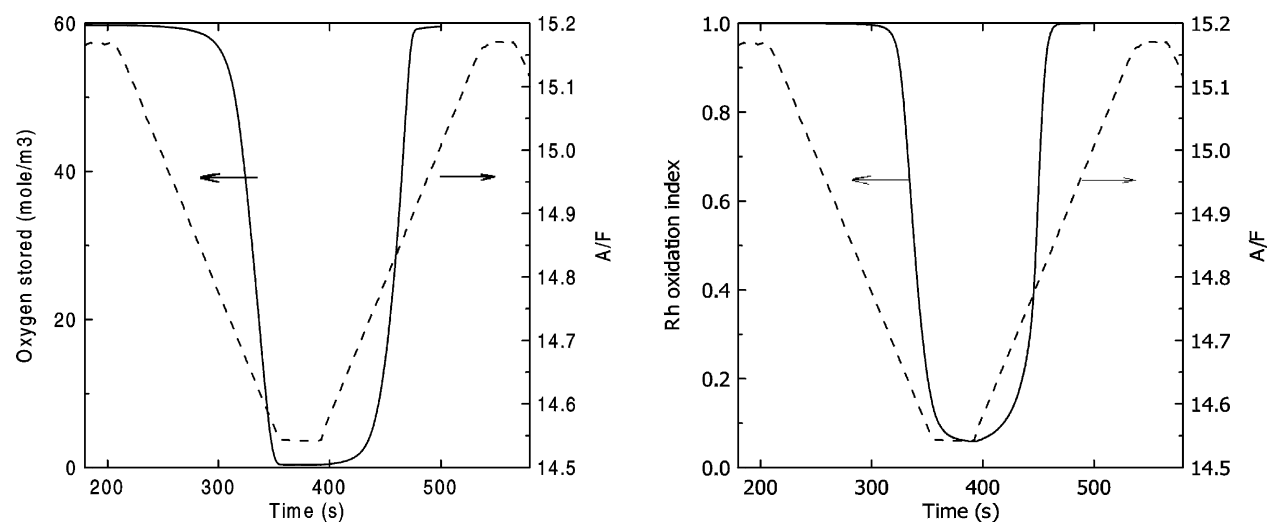

Fig. 5. Computed quantity of stored oxygen and $\mathrm{Rh}$ oxidation fraction during the $\mathrm{A} / \mathrm{F}$ scan test.

\section{Oscillating A/F scan}

As mentioned in the introduction, in conventional gasoline cars the catalytic converter operates at periodically oscillating $\mathrm{A} / \mathrm{F}$. The frequency and the width of the oscillation are determined by the response characteristics of the fuel management control loop. Several and often contradicting views have been expressed in the past, regarding the effect of the oscillation on catalyst efficiency (Cho, 1988; Muraki et al., 1985; Shinjoh et al., 1989; Cho and West, 1986). In the interesting review of Silveston (1996) it is concluded that the periodic oscillations are beneficial during the cold start phase, when the catalyst operates at low temperatures, but they can be unfavorable at high-temperature operation. However, we can not consider the above statement as a general rule, 

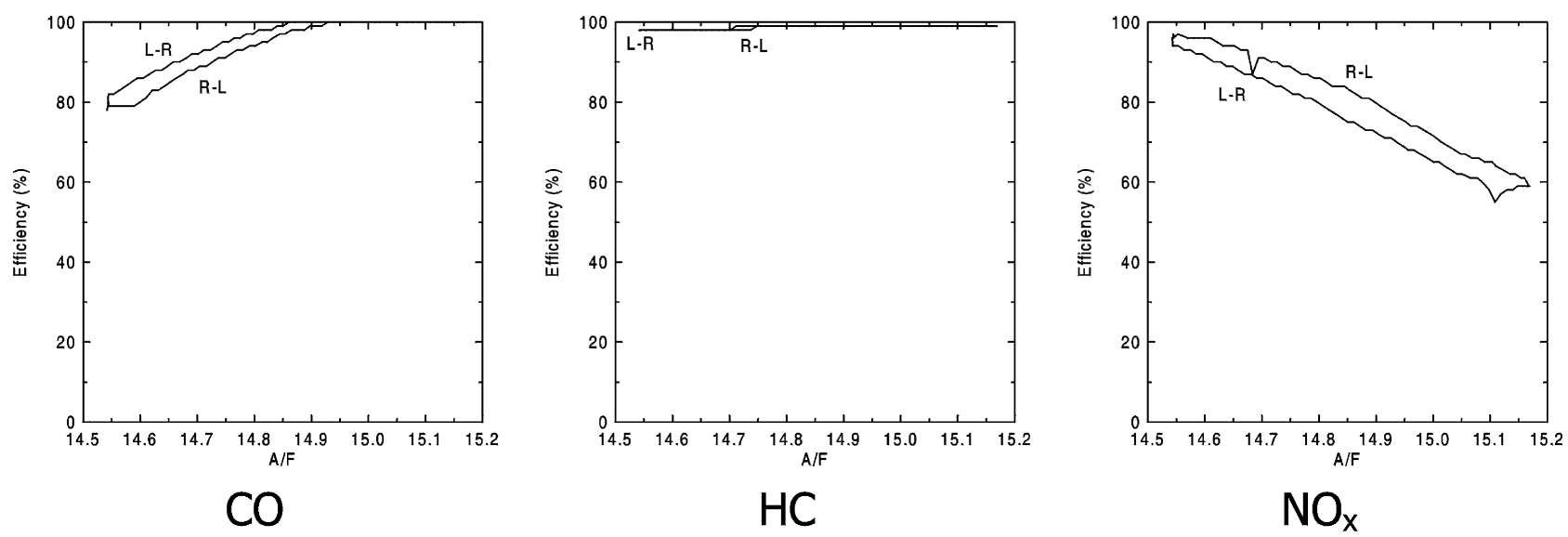

Fig. 6. Measured catalyst efficiencies as functions of mean A/F value during A/F scan with superimposed oscillation.

since the operating parameters that determine the final effect are numerous and sometimes interacting with each other. These parameters are:

- Catalyst precious metal loading and composition.

- Loading and dispersion of oxygen storage components.

- Catalyst temperature.

- Feed gas flow rate.

- A/F oscillation frequency.

- A/F oscillation amplitude.

- Mean value of $\mathrm{A} / \mathrm{F}$ oscillation.

The number of these parameters can be even larger if we consider other possible forms of oscillation, e.g. with different times in the lean and rich region. The large number of possible combinations renders the problem of optimizing fuel management very difficult to solve. In practice, most of modern fuel management systems aim at keeping $\mathrm{A} / \mathrm{F}$ as close as possible to stoichiometry. However, given the capabilities offered by modern electronic control units, it is believed, that there exists a significant margin to optimize such systems, by exploiting $\mathrm{A} / \mathrm{F}$ oscillations.

In the following, the catalyst behavior is studied experimentally and computationally in a single $\mathrm{A} / \mathrm{F}$ scan test, during which an $\mathrm{A} / \mathrm{F}$ oscillation is superimposed (amplitude $0.9 \mathrm{~A} / \mathrm{F}$, frequency $0.5 \mathrm{~Hz}$ ). The measured conversion efficiencies for the three species as functions of the mean $\mathrm{A} / \mathrm{F}$ value are presented in Fig. 6. We can remark the following:

- As in the case with no oscillation, the efficiency depends on the direction to which the scan is realized, although the lag here is smaller.

- $\mathrm{A} / \mathrm{F}$ oscillations result in higher $\mathrm{CO}$ and $\mathrm{HC}$ efficiencies for substoichiometric $\mathrm{A} / \mathrm{F}$, which remain high in stoichiometry and oxygen abundance conditions. Es- pecially, HCs are practically $100 \%$ converted in the whole scan range. However, $\mathrm{CO}$ efficiency at stoichiometry is $85-95 \%$, compared to the $100 \%$ of the no oscillation case.

- The A/F oscillation is clearly beneficial for NO conversion at lean operation and remains high in the rich region. At stoichiometry, the efficiency is significantly lower than $100 \%$.

The results of the mathematical model in the case of the above experiment are given in Fig. 7. In the same figure, we present the results of a simulation, without taking account of the dynamic submodels (oxygen storage and water-gas reaction). In fact, the latter results describe the 'quasi-steady' behavior of the catalyst. It is obvious, that the effects of the dynamic phenomena in this test are very important and actually favorable for catalyst efficiency. At the same time, we can observe that the model results compare well with the respective experimentally measured. Of course, an exact quantitative prediction was not expected, taking into account, that:

- The assumptions underlying the dynamic submodels are fairly simplistic, due to lack of sufficient kinetic studies in the field.

- To our knowledge, this is the first trial presented in the literature to predict such aspects of catalyst behavior.

- The basic aim of the work in this phase is to recognize and explain the phenomena in a qualitative way.

Fig. 8 presents the stored oxygen and the $\mathrm{Rh}$ oxidation fraction during $\mathrm{A} / \mathrm{F}$ scan with oscillation, as computed by the mathematical model. The plots refer to the computed mean values averaged over a time period equal to the oscillation period. We can observe that both the stored oxygen and the Rh oxidation fraction are higher compared to the respective ones for the case with no oscillation. This is explained taking into account that the 


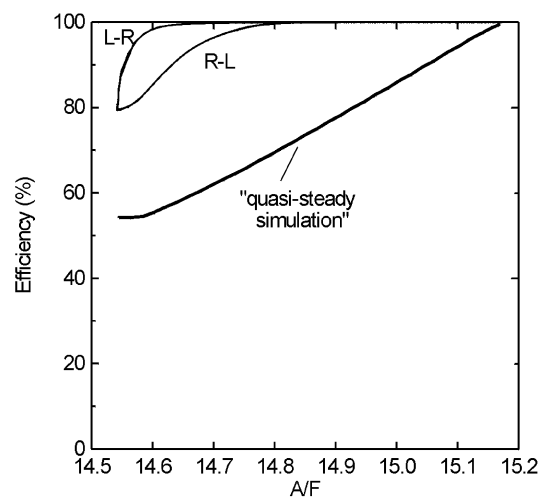

$\mathrm{CO}$

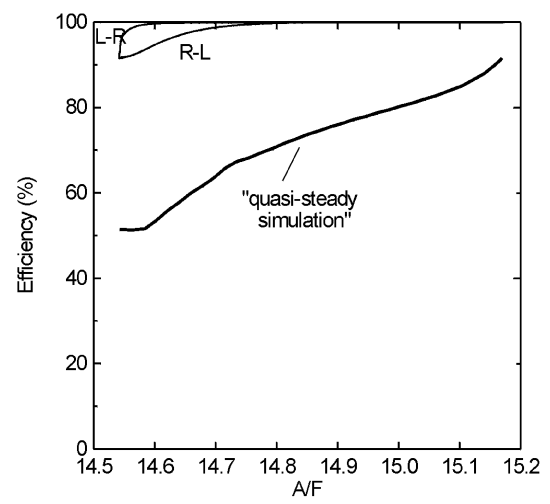

$\mathrm{HC}$

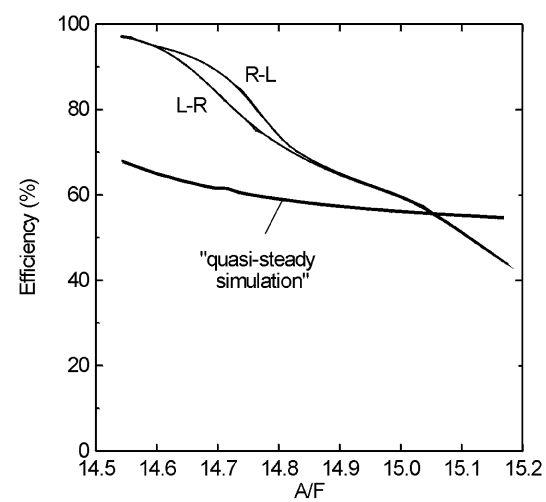

$\mathrm{NO}_{\mathrm{x}}$

Fig. 7. Computed catalyst conversion efficiencies as functions of A/F during A/F scan with oscillation. Results of quasi-steady simulations are also presented.
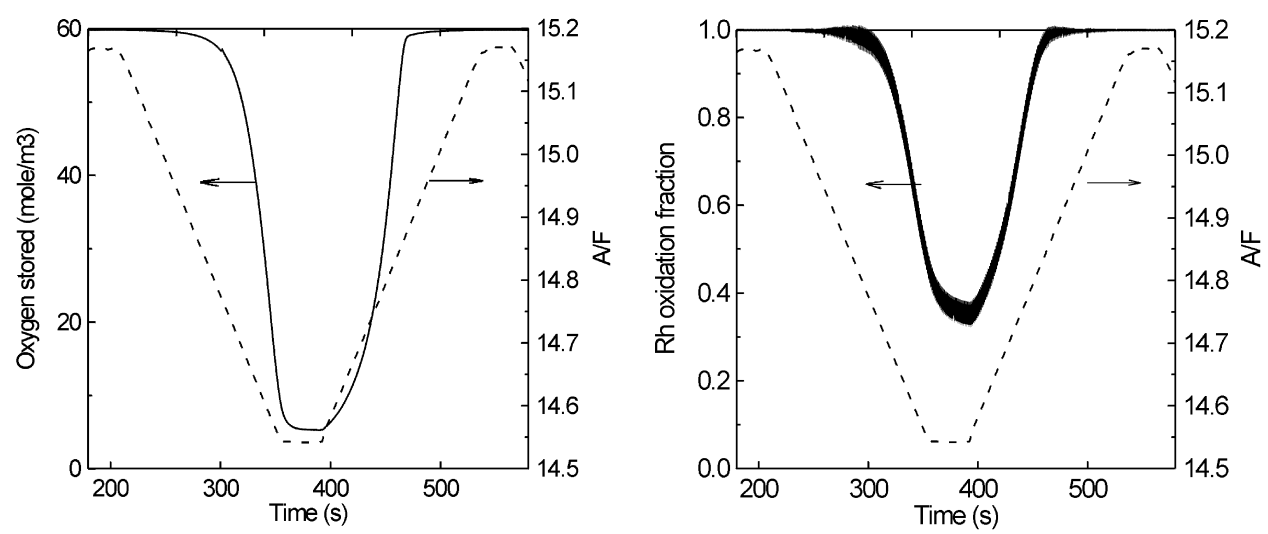

Fig. 8. Computed quantity of stored oxygen and Rh oxidation fraction during A/F scan with oscillation.

oxidation rates for the involved reactions are higher than the respective rates for the reduction reactions.

\section{Concluding remarks}

3-way catalytic converter operation under highly transient exhaust gas composition changes can not be sufficiently predicted using quasi-steady approaches, which are followed by the majority of models presented in the literature. Mathematical models, which simulate transient adsorption - desorption phenomena could be employed to solve the problem, but they are extremely demanding in terms of input data. Furthermore, the theoretical assumptions of such models are probably questionable in automotive exhaust environment.

In this work, a quasi-steady model is equipped with dynamic submodels of the basic dynamic phenomena. Following the literature experience, as well as related computational investigations, oxygen storage and transient water-gas shift activity are recognized as the important dynamic phenomena and modeled with simple reaction schemes. It was concluded that the submodels offered good prediction capabilities, at least qualitatively, for a wide operating range.

A set of experimental tests and the respective model runs were exploited to investigate the critical aspects of 3-way catalyst transient behavior in realistic operating conditions. In the A/F scan test, a significant dependence on the scan direction was found. This was attributed to the combined action of the dynamic phenomena and quantitatively explained by the mathematical model.

The A/F oscillation, which is of high practical interest was investigated experimentally and computationally in a selected test case, during an $\mathrm{A} / \mathrm{F}$ scan. In the specific test, it was found that the oscillation was beneficial for $\mathrm{CO}$ and $\mathrm{HC}$ at rich conditions, as well as for $\mathrm{NO}$ at lean conditions. At stoichiometry, the conversion efficiency for all three species is slightly lower. With the aid of model simulations, the effects of $\mathrm{A} / \mathrm{F}$ oscillations were recognized and explained. The beneficial effect of $\mathrm{A} / \mathrm{F}$ oscillations was attributed on the higher oxidation rates observed in the oxygen storage and $\mathrm{Rh}$ redox reactions compared to the respective reduction rates. This results 
in a higher level of Rh oxidation fraction as well as higher stored oxygen availability, compared to the case with no A/F oscillation.

The main aim of this work was to illustrate an alternative approach for the study and modeling of the $3 \mathrm{WCC}$ operation under severe transients, presenting some initial results. Further work is scheduled, in order to validate the approach in a wider application field. This would enable an efficient parametric analysis, aiming at fine tuning of the engine-converter system with optimum emission control.

\section{Notation}

3WCC 3-way catalytic converter

A reaction rate constant, $\mathrm{mol} \mathrm{K} / \mathrm{m}^{3} \mathrm{~s}$

$\mathbf{c}_{s} \quad$ vector of species concentrations, mole fraction

$c \quad$ species concentration, mole fraction

$C_{p} \quad$ specific heat capacity, $\mathrm{J} / \mathrm{kg} \mathrm{K}$

$\Delta H \quad$ heat of adsorption, $\mathrm{J} / \mathrm{mol}$

$G \quad$ inhibition factor, $\mathrm{K}$

HC Hydrocarbon

$k_{\mathrm{ox}} \quad$ oxidation rate constant, $\mathrm{mol} / \mathrm{m}^{3} \mathrm{~s}$

$k_{\text {red }} \quad$ reduction rate constant, $\mathrm{mol} / \mathrm{m}^{3} \mathrm{~s}$

$K \quad$ adsorption equilibrium constant

$K_{p} \quad$ chemical equilibrium constant

$\dot{n} \quad$ molecular flux, $\mathrm{mol} / \mathrm{m}^{3} \mathrm{~s}$

$R \quad$ reaction rate or gas constant, $\mathrm{mol} / \mathrm{m}^{3} \mathrm{~s}$ or $\mathrm{J} / \mathrm{mol} \mathrm{K}$

$\begin{array}{ll}t & \text { time, } \mathrm{s} \\ T & \text { temperature, } \mathrm{K}\end{array}$

$x \quad$ carbon atoms in the hydrocarbon molecule

$y \quad$ hydrogen atoms in the hydrocarbon molecule

Greek letters

$\psi \quad$ oxidation fraction

\section{Subscripts}

$\begin{array}{ll}\text { cap } & \text { capacity } \\ g & \text { exhaust gas } \\ i & \text { space node index } \\ j & \text { indication of exhaust species } \\ k & \text { indication of reaction } k \text { (equations) } \\ \text { ox } & \text { oxidation } \\ \text { red } & \text { reduction } \\ s & \text { solid }\end{array}$

\section{Appendix A}

Reactions considered in the mathematical model:

$\mathrm{CO}+\frac{1}{2} \mathrm{O}_{2} \rightarrow \mathrm{CO}_{2}$,

$$
\begin{aligned}
& \mathrm{H}_{2}+\frac{1}{2} \mathrm{O}_{2} \rightarrow \mathrm{H}_{2} \mathrm{O}, \\
& \mathrm{C}_{x} \mathrm{H}_{y}+\alpha \mathrm{O}_{2} \rightarrow \beta \mathrm{CO}_{2}+\gamma \mathrm{H}_{2} \mathrm{O}-\text { fast } \mathrm{HC}, \\
& \mathrm{C}_{x} \mathrm{H}_{y}+\alpha \mathrm{O}_{2} \rightarrow \beta \mathrm{CO}_{2}+\gamma \mathrm{H}_{2} \mathrm{O}-\text { slow } \mathrm{HC}, \\
& \mathrm{CO}+\mathrm{H}_{2} \mathrm{O} \rightarrow \mathrm{CO}_{2}+\mathrm{H}_{2}, \\
& 2 \mathrm{CO}+2 \mathrm{NO} \rightarrow \mathrm{CO}_{2}+\mathrm{N}_{2} .
\end{aligned}
$$

The rate expressions employed in the above reactions are the following:

$$
\begin{aligned}
& R_{1}=\frac{A_{1} \mathrm{e}^{-E_{1} / R T} c_{\mathrm{CO} c_{\mathrm{O}_{2}}}}{G_{1}\left(T_{S}, c_{S}\right) G_{3}\left(T_{S}, c_{\mathrm{C}_{2} \mathrm{H}_{2}}\right)} \\
& R_{2}=\frac{A_{2} \mathrm{e}^{-E_{2} / R T} c_{\mathrm{H}_{2}} c_{\mathrm{O}_{2}}}{G_{1}\left(T_{S}, c_{S}\right) G_{3}\left(T_{S}, c_{\mathrm{C}_{2} \mathrm{H}_{2}}\right)} \\
& R_{3}=\frac{A_{3} \mathrm{e}^{-E_{3} / R T} c_{\mathrm{C}_{3} \mathrm{H}_{6}} C_{\mathrm{O}_{2}}}{G_{1}\left(T_{S}, c_{S}\right) G_{3}\left(T_{S}, c_{\mathrm{C}_{2} \mathrm{H}_{2}}\right)} \\
& R_{3}=\frac{A_{3} \mathrm{e}^{-E_{3} / R T} c_{\mathrm{C}_{3} \mathrm{H}_{6}} C_{\mathrm{O}_{2}}}{G_{1}\left(T_{S}, c_{S}\right) G_{3}\left(T_{S}, c_{\mathrm{C}_{2} \mathrm{H}_{2}}\right)} \\
& R_{5}=\theta_{\mathrm{Rh}} \frac{A_{5} \mathrm{e}^{-E_{5} / R T} c_{\mathrm{CO} c_{\mathrm{H}_{2} \mathrm{O}}}}{G_{1}\left(T_{S}, c_{S}\right) G_{3}\left(T_{S}, c_{\mathrm{C}_{2} \mathrm{H}_{2}}\right)} \mathrm{Eq}_{5} \\
& R_{6}=\frac{A_{6} \mathrm{e}^{-E_{6} / R T} c_{\mathrm{CO}}^{-0.2} c_{\mathrm{NO}}^{0.5}}{G_{2}\left(T_{S}, c_{S}\right) G_{3}\left(T_{S}, c_{\mathrm{C}_{2} \mathrm{H}_{2}}\right)}
\end{aligned}
$$

with the following expressions accounting for the inhibition terms:

$$
\begin{aligned}
G_{1}= & T_{s}\left(1+K_{a 1} c_{\mathrm{CO}}+K_{a 2} c_{\mathrm{C}_{3} \mathrm{H}_{6}}\right)^{2}\left(1+K_{a 3} c_{\mathrm{CO}^{2}}^{2} c_{\mathrm{C}_{3} \mathrm{H}_{6}}^{2}\right) \\
& \times\left(1+K_{a 4} c_{\mathrm{NO}}^{0.7}\right), \\
G_{2}= & T_{S}^{-0.17}\left(T_{S}+K_{a 5} c_{\mathrm{CO}}\right)^{2}, \\
G_{3}= & 1+K_{a 6} c_{\mathrm{C}_{2} \mathrm{H}_{2}} .
\end{aligned}
$$

To account for the chemical equilibrium of the water-gas shift reaction, an additional factor is considered in the respective reaction rate expression:

$\mathrm{Eq}_{5}=1-\frac{c_{s, \mathrm{CO}_{2}} c_{s, \mathrm{H}_{2}}}{c_{\mathrm{CO} c_{\mathrm{H}_{2} \mathrm{O}} K_{p}(T)}}$

The expressions for the adsorption equilibrium constants

$k_{a j}=k_{a 0 j} \exp \left[-\Delta H_{a j} / R T_{s}\right], \quad j=1, \ldots, 6$.

are employed (see Tables 2-4). 
Table 2

\begin{tabular}{lll}
\hline Constant & $\begin{array}{l}\text { Adsorption heat } \\
(\mathrm{J} / \mathrm{mol})\end{array}$ & $\begin{array}{l}\text { Adsor ption } \\
\text { factor } k a_{0 j}(-)\end{array}$ \\
\hline$K_{a 1}$ & -7990 & 65.5 \\
$K_{a 2}$ & $-3 \times 10^{5}$ & $2.08 \times 10^{3}$ \\
$K_{a 3}$ & $-9.65 \times 10^{4}$ & 3.98 \\
$K_{a 4}$ & $3.1 \times 10^{4}$ & $4.79 \times 10^{5}$ \\
$K_{a 5}$ & $-5.43 \times 10^{3}$ & $1.2028 \times 10^{5}$ \\
$K_{a 6}$ & $-7.145 \times 10^{4}$ & 20 \\
\hline
\end{tabular}

Table 3

\begin{tabular}{lll}
\hline Reaction & $\begin{array}{l}\text { Activation energy } E_{i} \\
(\mathrm{~J} / \mathrm{mol})\end{array}$ & $\begin{array}{l}\text { Activity factor } A_{i} \\
\left(\mathrm{~mol} \mathrm{~K} / \mathrm{m}^{2} \mathrm{~s}\right)\end{array}$ \\
\hline 1 & 95,000 & $2 \times 10^{13}$ \\
2 & 95,000 & $2 \times 10^{13}$ \\
3 & 105,000 & $3 \times 10^{14}$ \\
4 & 125,000 & $4 \times 10^{14}$ \\
5 & 105,000 & $6 \times 10^{8}$ \\
6 & 70,000 & $5 \times 10^{6}$ \\
\hline
\end{tabular}

Table 4

Kinetic constants of dynamic submodels

\begin{tabular}{ll}
\hline Pre-exponential factors $\left(\mathrm{mol} / \mathrm{m}^{2} \mathrm{~s}\right)$ & Activation energies $(\mathrm{J} / \mathrm{mol})$ \\
\hline$A_{\mathrm{ox}}=3 \times 10^{5}$ & $E_{\text {ox }}=90,000$ \\
$A_{\text {red,CO }}=1.5 \times 10^{5}$ & $E_{\text {red,CO }}=90,000$ \\
$A_{\text {red,HC }}=2.6 \times 10^{5}$ & $E_{\text {red,HC }}=90,000$ \\
$A_{\mathrm{Rh}, \mathrm{ox}}=3.5 \times 10^{4}$ & $E_{\mathrm{Rh}, \mathrm{ox}}=80,000$ \\
$A_{\mathrm{Rh}, \mathrm{red}}=2 \times 10^{4}$ & $E_{\mathrm{Rh}, \mathrm{red}}=80,000$ \\
\hline
\end{tabular}

\section{Appendix B}

Geometric and thermophysical properties of the 3WCC employed in the experiments and computations

Noble metal composition

Noble metal loading

Monolith frontal area

Monolith length

Channel density

Substrate thickness

Washcoat layer thickness

Substrate density

Washcoat density

Monolith conductivity

Monolith specific thermal capacity

Insulation thickness

Insulation density

Insulation thermal conductivity

Insulation specific heat capacity

Heat convection coefficient to ambient

Emissivity of converter outer shell

Oxygen storage capacity

$\begin{array}{ll}\mathrm{Pt} / \mathrm{Pd} / \mathrm{Rh} & \\ 110 & \mathrm{~g} / \mathrm{ft}^{3} \\ 5.067 \times 10^{-4} & \mathrm{~m}^{2} \\ 0.076 & \mathrm{~m} \\ 400 & \mathrm{channels} / \mathrm{in}^{2} \\ 0.154 \times 10^{-3} & \mathrm{~m} \\ 0.025 \times 10^{-3} & \mathrm{~m} \\ 1800 & \mathrm{~kg} / \mathrm{m}^{3} \\ 1000 & \mathrm{~kg} / \mathrm{m}^{3} \\ 1.5 & \mathrm{~W} / \mathrm{m} \mathrm{K}^{3} \\ 1020 & \mathrm{~J} / \mathrm{kg} \mathrm{K} \\ 3 \times 10^{-3} & \mathrm{~m} \\ 1000 & \mathrm{~kg} / \mathrm{m}^{3} \\ 0.5 & \mathrm{~W} / \mathrm{mK}^{3} \\ 600 & \mathrm{~J} / \mathrm{kg} \mathrm{K} \\ 45 & \mathrm{~W} / \mathrm{m}^{2} \mathrm{~K} \\ 0.3 & \\ 60 & \mathrm{~mol} / \mathrm{m}^{3} \\ & \end{array}$

\section{References}

Bozek, J. W., Evans, R., Tyree, C. D., \& Zerafa, K. I. (1992). Operating characteristics of zirconia galvanic cells (lambda sensors) in automotive closed-loop emission control systems, SAE paper 920289.

Barbier Jr., J., \& Duprez, D. (1992). Hydrogen formation in propane oxidation on $\mathrm{Pt}-\mathrm{Rh} / \mathrm{CeO}_{2} / \mathrm{Al}_{2} \mathrm{O}_{3}$ catalysts. Applied Catalysis A: General, 85, 89-100.

Barshad, Y., \& Gulari, E. (1985). A dynamic study of CO oxidation over supported Platinum. American Institute of Chemical Engineers Journal, 31, 649-658.

Cho, B. K. (1988). Performance of $\mathrm{Pt} / \mathrm{Al}_{2} \mathrm{O}_{3}$ catalysts in automobile engine exhaust with oscillatory air/fuel ratio. Industrial and Engineering Chemistry Research, 27, 30-36.

Cho, B. K., \& West, L. A. (1986). Cyclic operation of $\mathrm{Pt} / \mathrm{Al}_{2} \mathrm{O}_{3}$ catalysts for $\mathrm{CO}$ oxidation. Industrial and Engineering Chemistry Fundamentals, 25, 158-164.

Dictor, R. (1987). A kinetic study of the water-gas shift reaction over $\mathrm{Rh} / \mathrm{Al}_{2} \mathrm{O}_{3}$ catalysts. Journal of Catalysis, 106, 458-4634.

Diwell, A. F., Rajaram, R. R., Shaw, H. A., \& Truex, T. J. (1991). The role of ceria in three-way catalysts. Catalysis and automotive pollution control II. Amsterdam: Elsevier Science Publishers B.V.

Herz, R. K. (1981). Dynamic behavior of automotive catalysts. 1. Catalyst oxidation and reduction. Industrial and Engineering Chemistry Production Research Development, 20, 451-457.

Herz, R. K. (1987). Dynamic behavior of automotive three-way emission control systems. Catalysis and automotive pollution control (p. 427). Amsterdam: Elsevier Science Publishers B.V.

Herz, R. K., Klela, J. B., \& Sell, J. A. (1983). Dynamic behavior of automotive catalysts. 2. Carbon monoxide conversion under transient air/fuel ratio conditions. Industrial and Engineering Chemistry Production Research and Development, 22, 387-396.

Herz, R. K., \& Sell, J. A. (1985). Dynamic behavior of automotive catalysts - III. Transient enhancement of water-gas shift over rhodium. Journal of Catalysis, 94, 166-174.

Koltsakis, G. C. (1996). Theoretical and experimental investigation of the 3-way catalytic converter dynamic behavior. Ph.D. thesis, Thessaloniki.

Koltsakis, G. C., Konstantinidis, P. A., \& Stamatelos, A. M. (1997). Development and application range of mathematical models for 3-way catalytic converters. Applied Catalysis B: Environmental, 12, 161-191.

Matsunaga Schin-ichi, Yokota, K., Muraki, H., \& Fujitani, Y. (1987). Improvement of engine emissions over three-way catalyst by the periodic operations. SAE paper 872098

Muraki, H., Shinjoh, H., Sobukawa, H., Yokota, K., \& Fujitani, Y. (1985). Behavior of automotive noble metal catalysts in cycled feedstreams. Industrial and Engineering Chemistry Production Research Development, 24, 43-49.

Nievergeld, A. J. L., Hoebink, J. H. B. J., \& Marin, G. B. (1994). The performance of a monolithic catalytic converter of automotive exhaust gas with oscillatory feeding of $\mathrm{CO}, \mathrm{NO}$ and $\mathrm{O}_{2}$ : A modelling study. Catalysis and automotive pollution control III. Amsterdam: Elsevier Science Publishers B.V.

Nunan, J. G., Robota, H. J., Cohn, M. J., \& Bradley, S. A. (1991). Physico-chemical properties of Ce-containing three-way-catalysts and the effect of $\mathrm{Ce}$ on catalyst activity. Catalysis and automotive pollution control II. Amsterdam: Elsevier Science Publishers B.V.

Oh, S. H., \& Cavendish, J. C. (1985), Mathematical modeling of catalytic converter lightoff - Part III: Prediction of vehicle exhaust emissions and parametric analysis. The American Institute of Chemical Engineers Journal, 31(6), pp. 943-949.

Oh, S. H., Fisher, G. B., Carpenter, J. E., \& Goodman, D. W. (1986). Journal of Catalysis, 100, 360-376.

Pattas, K. N., Stamatelos, A. M., Pistikopoulos, P. K., Koltsakis, G. C., Konstantinidis, P. A., Volpi, E., \& Leveroni, E. (1994). Transient modeling of 3-way catalytic converters. SAE paper 940934. 
Shinjoh, H., Muraki, H., \& Fujitani, Y. (1989). Periodic operation effects in propane and propylene oxidation over noble metal catalysts. Applied Catalysis, 49, 195-204.

Schlatter, J. C., \& Mitchell, P. J. (1980). Three-way catalyst response to transients. Industrial and Engineering Chemistry Production Research Development, 19, 288.

Schlatter, J. C., Sinkevitch, R. M., \& Mitchell, P. J. (1983). Laboratory reactor system for three-way automotive catalyst evaluation. Industrial and Engineering Chemistry Production Research Development, 22, 51-56.

Shulman, M. A., Hamburg, D. R., \& Throop, M. J. (1982). Comparison of measured and predicted three-way catalyst conversion efficiencies under dynamic air-fuel ratio conditions. SAE paper 820276.

Siemund, S., Leclerc, J. P., Schweich, D., Prigent, M., \& Castagna, F. (1996). Three-way monolithic converter: simulations versus experiments. Chemical Engineering Science, 51(15), 3709-3720.

Silveston, P. L. (1996). Automotive exhaust catalysis: Is periodic operation beneficial? Chemical Engineering Science, 51(10), 2419-2426.

Su, E. C., \& Rothchild, W. G. (1986). Dynamic behavior of three-way catalysts. Journal of Catalysis, 99, 506-510.

Taylor, K. C., \& Sinkevitch, R. M. (1983). Behavior of automobile exhaust catalysts with cycled feedstreams. Industrial and Engineering Chemistry Production Research Development, 22, 45-51. 